\title{
The strength effects of synthetic zeolites on properties of high performance concrete
}

\author{
P. Frontera ${ }^{1}$, S. Marchese ${ }^{1}$, F. Crea ${ }^{1}$, R. Aiello ${ }^{1}$ \& J. B. Nagy ${ }^{2}$ \\ ${ }^{1}$ Department of Chemical Engineering and Materials, \\ University of Calabria \\ ${ }^{2}$ Laboratoire de RMN, Facultés Universitaires Notre-Dame de la Paix
}

\begin{abstract}
The influence of several kinds of synthetic zeolite as mineral admixtures on the workability and performance strength of mortars cement and concrete has been investigated. In the first series of experiments zeolites have been used to replace $10 \%$ of cement in the preparation of mortars. The second series of experiments have regarded the preparation of high performance concrete. In order to evaluate the influence of alkali cations, two different forms of zeolite A have been used with one sodium $(\mathrm{NaA}$ or $4 \mathrm{~A})$ and the other with calcium $(\mathrm{CaA}$ or $5 \mathrm{~A})$ and also to evaluate the filling effects of particles zeolites $4 \mathrm{~A}$ and $5 \mathrm{~A}$ with different crystals sizes have been used. Furthermore we have used three types of cement with a different content of clinker: CEM I 42.5R, CEM II/A-S 42.5 R and CEM III/A-S $42.5 \mathrm{~N}$. Every prepared sample has been water-cured at $20^{\circ} \mathrm{C}$ for 2,7 and 28 days. The results of samples (mortars and concrete) made with zeolites were compared with those obtained with silica fume, usual fine material used in the preparation of high performance strength concrete.
\end{abstract}

Keywords: admixtures, zeolites, mortars, concrete, compressive strength.

\section{Introduction}

High strength concrete exhibits the rheological, mechanical and durability properties better than those of conventional concrete. The use of high concrete results in many advantages, such as reduction in beam and column sizes and increase in the building height. Moreover high strength concrete can perform much better in extreme and adverse climatic condition, reducing maintenance and repair costs. Silica fume is among one of the most recent pozzolanic 
materials currently used in high performance concrete production, this material is a by-product of the manufacture of silicon of various silicon alloys. The use of silica fume is very expensive, because it is light and has a low bulk density, which may cause difficult in transporting and handling.

The goal of this research was to study production and utilization of alternative materials that is suitable for use in concrete industries as a substitute for the expensive silica fume. The material examined has been the synthetic zeolites (LTA, FAU), with different content of alkali cation $\left(\mathrm{Na}^{+}, \mathrm{Ca}^{++}\right)$and micronic particles size. The structure of the natural and synthetic zeolitic materials is characterized by a large number of channels and cavities which exhibit a high surface area. The natural zeolites are hydrated alumino-silicate minerals containing alkaline and alkaline-earth metals, formed by the alteration of volcanic ash which is mainly an amorphous, siliceous material. They are considered as materials with high pozzolanic activity for their open structure and chemistry [1-5]. The pozzolanic activity of zeolites depends on the presence of reactive $\mathrm{SiO}_{2}$ and $\mathrm{Al}_{2} \mathrm{O}_{3}$ which react with the $\mathrm{Ca}(\mathrm{OH})_{2}$ liberated during the hydratation of cement and converting it into C-S-H gels and aluminates. As a result, the microstructure of hardened cement concrete is improved and the concrete becomes more impervious. In fact, a work of Chan et al., found that the use of natural zeolites as admixtures in concrete concurs to make high performance concrete (HPC concrete with high strength over $80 \mathrm{MPa}$ ), that usually are obtained with admixtures such as silica and fly ash [5].

In literature numerous reports exist on the use of natural zeolites in the concrete [7-11], little work instead consider the use of synthetic zeolites in cement industry [12-14]. This is probably linked with the wide availability of natural zeolites that economically concur being more favourable for large scale applications. However, the limit in the use of natural zeolites is in the fact that they have variable chemical compositions depending on their origin, and in addition, variable amounts of impurities can be present. Another limitation is that the natural zeolitic material before being used as additives in concretes must be finely crushed. For this reason we use the synthetic zeolites in form of powders, with fixed chemical compositions, which have also a low cost.

In this work the effect of synthetic zeolite A has been examined, in particular the zeolite 4A and 5A, which differ for the presence of $\mathrm{Ca}^{++}$cations. Moreover, crystals with different sizes have been used in order to evaluate the filling effect of the particles.

\section{Experimental}

\subsection{Materials}

- Portland cement CEM I 32.5 R with content of clinker $>95 \%$ (UNI EN 197/1).

- Portland- slag cement CEM II/A-S $42.5 \mathrm{R}$ with content of clinker between 80 and $94 \%$ and content of slag ranging between 6-20\%( (UNI EN 197/1).

- Blastfurnace cement CEM III /A-S $42.5 \mathrm{~N}$ with content of clinker between 35 and 94\% and slag ranging between 6 and $65 \%$ (UNI EN 197/1). 
Four different synthetic zeolites were prepared: two of which having small particle size:

- $\quad$ zeolite 4A with size of crystals ranging about 1-5 $\mu \mathrm{m}\left(\mathbf{N a A}_{\mathbf{L}}\right)$ (Fig.1).

- $\quad$ zeolite 4A with size of crystals ranging about 0.2-1 $\mu \mathrm{m}\left(\mathbf{N a A _ { \mathbf { S } }}\right)$ (Fig.2).

- $\quad$ zeolite 5A with size of crystals ranging about 1-5 $\mu \mathrm{m}\left(\mathbf{C a A}_{\mathbf{L}}\right)$ (Fig.1).

- $\quad$ zeolite 5A with size of crystals ranging about 0.2-1 $\mu \mathrm{m}\left(\mathbf{C a A} \mathbf{A}_{\mathbf{S}}\right)$ (Fig.2).

Silica Fume (SF) (trade name MAPEPLAST SF) produced and supplied by MAPEI (Italy).

Coarse Aggregate rounded with $25 \mathrm{~mm}$ maximum diameter in accordance with UNI 8520-2.

Fine Aggregate is standard sand in accordance with UNI EN 933-3.

The Superfludifiant used was acrylic polymers without formaldehyde with 30.5 solid content (trade name Dynamon SP1) produced and supplied by MAPEI (Italy).

\subsection{Preparation of zeolites}

The small crystals of zeolites $4 \mathrm{~A}$ were prepared starting from the following initial reaction mixture: $2.37 \mathrm{Na}_{2} \mathrm{O} 1 \mathrm{Al}_{2} \mathrm{O}_{3} 1.90 \mathrm{SiO}_{2} 62 \mathrm{H}_{2} \mathrm{O}$

The synthesis procedure was the following: sodium aluminate was added to a solution of sodium hydroxide solution and after the homogenisation the silica source was added. The solution was stirred for $15 \mathrm{~min}$ at room temperature and then submitted to hydrothermal treatment, in static conditions, at $25^{\circ} \mathrm{C}$ for about 7 days.

The large crystals of zeolites $4 \mathrm{~A}$ were prepared starting from system having the composition: $3.2 \mathrm{Na}_{2} \mathrm{O} \quad 1 \mathrm{Al}_{2} \mathrm{O}_{3} 1.90 \mathrm{SiO}_{2} 95 \mathrm{H}_{2} \mathrm{O}$. The reagents admixture was made as described above. Successively, the solution obtained has been submitted to hydrothermal treatment at $95{ }^{\circ} \mathrm{C}$ for $2 \mathrm{~h}$, in stirred conditions.

After the hydrothermal treatment every samples are recovered, washed with distilled water, dried at $110^{\circ} \mathrm{C}$ for 12 hours and successively equilibrated at room temperature before $\mathrm{X}$-ray and microscope analysis.

The X Ray analysis confirms the presence of only zeolite A in all samples obtained.

Through microscope analysis it is possible to evaluate the different dimensions of crystals obtained (Fig.1, Fig.2).

The zeolites $5 \mathrm{~A}$ were prepared by ionic exchange of zeolite 4A, 250g of 4A have been contacted with 1 liter of a $1 \mathrm{M}$ aqueous solution of calcium nitrate at room temperature. This exchange procedure was applied three times. The efficiency of exchange has been checked by EDAX (Energy Dispersive X-Ray Analysis $)$, the zeolite $5 \mathrm{~A}$ obtained has a ratio of ionic content $\left(\mathrm{Ca}^{++} / \mathrm{Ca}^{++}+\right.$ $\left.\mathrm{Na}^{+}\right)$) of about 0.9 .

\subsection{Preparation of mortars}

Cement mortars were prepared for determination of compressive strength of the mixtures. Zeolites were used as direct replacement of cement on a weight to weight basis at the levels of $10 \%$. The sand/cement ratio was 3 and the 
water/solid ratio was 0.5 . To obtain the cement mortars all solid and water was mixed for 5 minutes and then cast in prismatic moulds.

The specimens were demolded after 24 hours of moist-curing at $23^{\circ} \mathrm{C}$.

Companion specimens were placed in water at $20^{\circ} \mathrm{C}$ after demolding. Compressive strength was determined at designated ages.
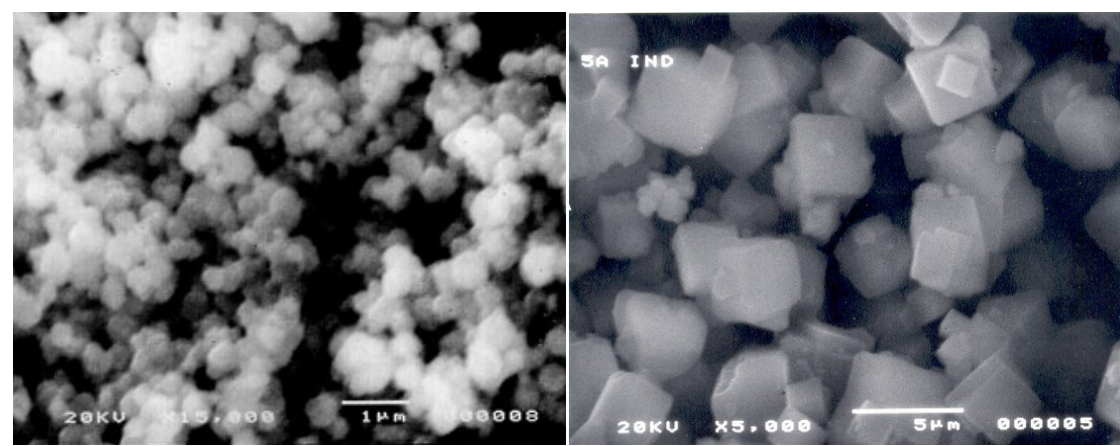

Figure 1: A) SEM micrographs of the small crystal of zeolite $A\left(\mathrm{NaA}_{\mathrm{S}}\right.$, $\left.\mathrm{CaA}_{\mathrm{S}}\right)$ B) SEM micrographs of the large crystal of zeolite $\mathrm{A}\left(\mathrm{NaA}_{\mathrm{L}}\right.$, $\mathrm{CaA}_{\mathrm{L}}$ ).

\subsection{Preparation of concrete}

The concrete mixtures were prepared at water to cementitious material ratio 0.35 . Zeolite was used in addition of cement on a weight to weight basis at the levels of $10 \%$. Also the concrete mixtures containing silica fume were prepared at a water-to cementitious ratio of 0.35 .

Cube specimens of concrete were cast in $100 \mathrm{~mm} \times 100 \mathrm{mmx} 100 \mathrm{~mm}$ standard moulds, respectively. The specimens were removed from the moulds after 1 day and were then cured in water at $20^{\circ} \mathrm{C}$ until the age of strength testing. The mix proportions of concrete prepared are shown in Table 1.

Table 1: $\quad$ Mixture proportions of concrete.

\begin{tabular}{|l|l|l|l|l|l|l|}
\hline \multicolumn{6}{|l|}{ Mix Proportion $\left(\mathrm{kg} / \mathrm{m}^{3}\right)$} \\
\hline W/C & Zeolite & water & Cement & $\begin{array}{l}\text { Fine } \\
\text { aggregate }\end{array}$ & $\begin{array}{l}\text { Course } \\
\text { Aggregate }\end{array}$ & Superfluidifiant \\
\hline 0,35 & 50 & 175 & 500 & 693 & 1040 & 5 \\
\hline
\end{tabular}

\subsection{Characterization and testing}

The compressive strength of the concrete and mortars were tested at the ages of 2, 7 and 28 days using a machine (MATEST in accordance with UNI 6686-1,2) the loading rate of $1000 \mathrm{~N} / \mathrm{mm}^{2} \mathrm{sec}$.

Moreover, in the case of preparation of concrete the workability has been measured, following the prescription of UNI 9418, we have executed the slump test on fresh concrete. 


\section{Results and discussions}

\subsection{Properties of mortars}

The results of the compressive strength test of the mortars are shown in Table 2.

Table 2: $\quad$ Compressive strength of mortars.

\begin{tabular}{|l|c|c|c|c|}
\hline & & \multicolumn{3}{|l|}{ Compressive strength (MPa) } \\
\hline Cement & Zeolites & 2 days & 7 days & 28 days \\
\hline CEM I & -- & 18.9 & 29.2 & 34.0 \\
\hline & $\mathrm{NaA}_{\mathrm{S}}$ & 17.7 & 21.2 & 25.3 \\
\hline & $\mathrm{NaA}_{\mathrm{L}}$ & 21.9 & 30.1 & 31.3 \\
\hline & $\mathrm{CaA}_{\mathrm{S}}$ & 26.1 & 34.5 & 36.2 \\
\hline & $\mathrm{CaA}_{\mathrm{L}}$ & 25.9 & 33.4 & 39.1 \\
\hline & $\mathrm{SF}$ & 20.3 & 29.5 & 36.4 \\
\hline CEM II/A-S & -- & 22.5 & 32.6 & 42.8 \\
\hline & $\mathrm{NaA}$ & 20.6 & 28.5 & 39.9 \\
\hline & $\mathrm{NaA}$ & 28.0 & 34.3 & 37.7 \\
\hline & $\mathrm{CaA}$ & 26.8 & 35.7 & 42.7 \\
\hline & $\mathrm{CaA}_{\mathrm{L}}$ & 30.0 & 37.2 & 42.8 \\
\hline & $\mathrm{SF}$ & 21.1 & 28.6 & 40.5 \\
\hline & -- & 15.7 & 23.5 & 42.5 \\
\hline & $\mathrm{NaA}_{\mathrm{S}}$ & 15.7 & 20.9 & 23.9 \\
\hline & $\mathrm{NaA}_{\mathrm{L}}$ & 20.4 & 26.7 & 30.5 \\
\hline & $\mathrm{CaA}_{\mathrm{S}}$ & 20.1 & 30.4 & 38.0 \\
\hline & $\mathrm{CaA}_{\mathrm{L}}$ & 22.3 & 32.6 & 40.8 \\
\hline & $\mathrm{SF}$ & 13.5 & 22.9 & 39.0 \\
\hline
\end{tabular}

The replacement of $10 \%$ of CEM I, with most of zeolites, generally improves the compressive strength of the mortars cement, both at early ages and longer. Only the zeolites $\mathrm{NaA}_{S}$ and $\mathrm{NaA}_{L}$ make worse the compressive strength of the mortars made with CEM I. The mortars prepared with CEM I and Zeolite $\mathrm{CaA}_{S}$ and $\mathrm{CaA}_{\mathrm{L}}$ exhibit compressive strength alike and higher, respectively, than the mortars with CEM I and silica fume.

In the case of CEM II/A-S, the replacement of $10 \%$ of this type of cement in the preparation of mortars with all zeolites and also with silica fume does not improve significantly the compressive strength at later ages as 28 days, but at early ages it is possible to remark an increase of compressive strength.

For the CEM III/A-S, that is a cement with a high content of fly ash with a low rate of hardening, the replacement of $10 \%$ of zeolites $\mathrm{NaA}_{L}, \mathrm{CaA}_{\mathrm{L}}, \mathrm{CaA}_{\mathrm{S}}$ improves the compressive strength at early ages, concurring to transform a cement of slow hardening in to a rapid hardening.

The increase in the strength of mortars due to the replacement of zeolites $\mathrm{CaA}_{\mathrm{S}}, \mathrm{CaA}_{\mathrm{L}}$ and silica fume can be attributed to the improved aggregate-matrix 
bond associated with formation of a less porous transition zone and a better interlock between the paste and sand.

Furthermore, the zeolitic materials with calcium ions play an important role in improving the fine aggregate-paste bond through the formation of more calcium hydrates as showed by microscope analysis (Fig. 2).

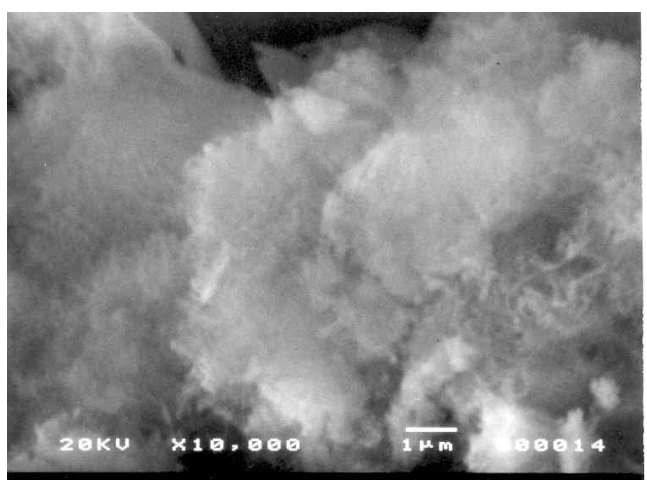

Figure 2: $\quad$ SEM micrograph of fibrous C-S-H (Calcium Silicate Hydrate) in the mortars made with zeolite $\mathrm{CaA}$.

\subsection{Properties of fresh concrete}

The concrete mixes were tested in the fresh state for the workability. The standard test measured the slump of fresh concrete and the results are summarized in figure 3 .

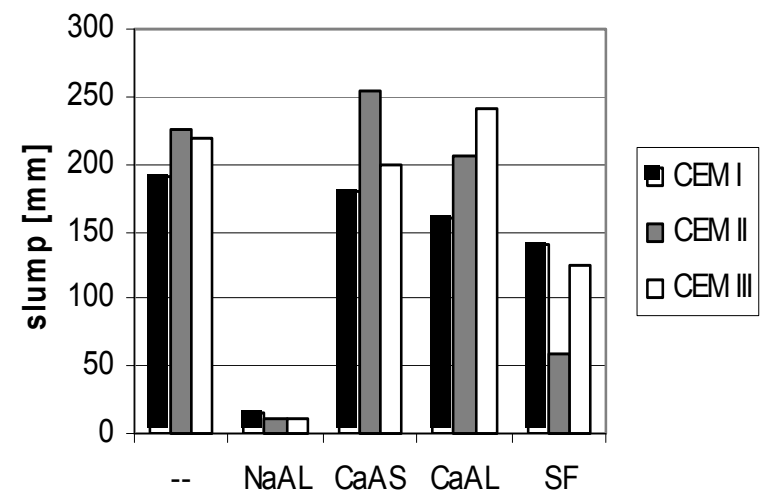

Figure 3: Workability of fresh concrete prepared with cements with and without $10 \%$ of various admixture.

According to these results, most of the concrete made with zeolites CaAs and $\mathrm{CaA}_{\mathrm{L}}$, had a high slump and were workable. In particular, the fresh concrete made with zeolites are more workable than that made with silica fume. This is 
probably caused by the presence of amount of water in zeolitic materials (20 weight $\%$ of zeolites).

The concretes made did not show tendencies to segregate or bleed much, because of the high total cementitious contents, including zeolites or silica fume and low water to cementitious ratio.

\subsection{Properties of hardened concrete}

For investigating the strength development of different concrete mixtures, the results of compressive tests are plotted in Figures 4-6.

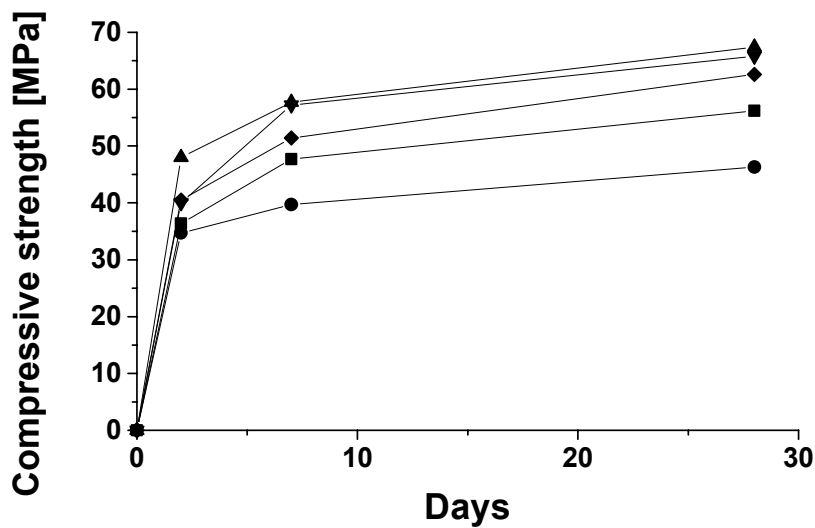

Figure 4: Compressive strength of concretes prepared with CEM I with and

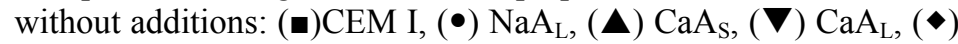
SF.

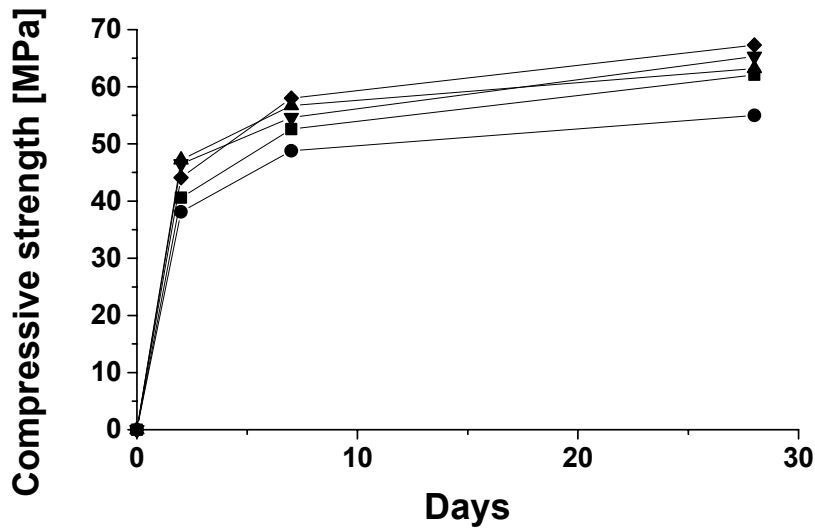

Figure 5: Compressive strength of concretes prepared with CEM II/A-S with and without additions: (๘)CEM II/A-S, (•) $\mathrm{NaA}_{\mathrm{L}},(\boldsymbol{\Delta}) \mathrm{CaA}_{\mathrm{S}},(\boldsymbol{\nabla})$ $\mathrm{CaA}_{\mathrm{L}},(\diamond) \mathrm{SF}$. 


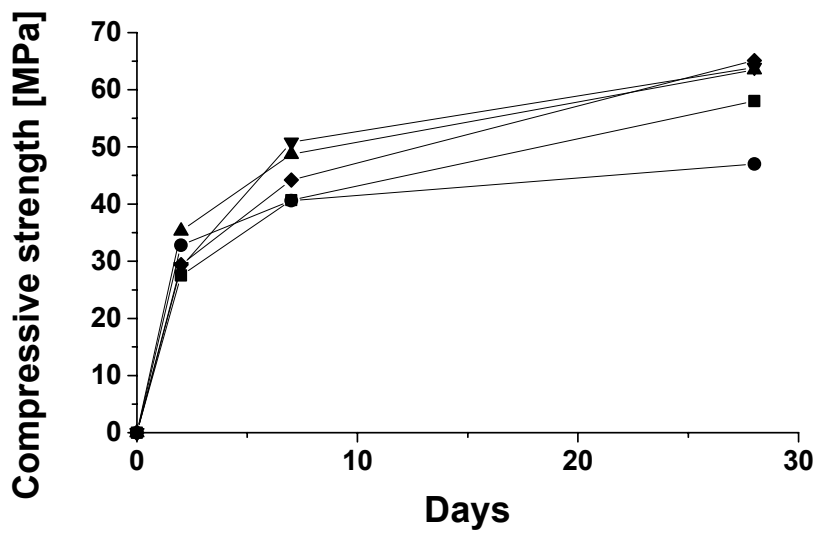

Figure 6: $\quad$ Compressive strength of concrete prepared with CEM III/A-S with and without additions $(\boldsymbol{\bullet}) \mathrm{CEM} \mathrm{III} / \mathrm{A}-\mathrm{S},(\bullet) \mathrm{NaA}_{\mathrm{L}},(\boldsymbol{\Delta}) \mathrm{CaA}_{\mathrm{S}},(\boldsymbol{\nabla})$ $\mathrm{CaA}_{\mathrm{L}},(\bullet) \mathrm{SF}$.

The concrete made with zeolites CEM I and both $\mathrm{CA}_{\mathrm{S}}$ and $\mathrm{CA}_{\mathrm{L}}$ exhibits comparable values of compressive strength at 2, 7 and 28 days. They do not have relevant differences caused by the size of the particles, probably due to the fact that at a ratio $\mathrm{a} / \mathrm{c}=0.35$ the pozzolanic effects of zeolites are more important than the effects of particles packing. Also it is possible to notice at early ages a more increment of compressive strength for samples prepared with zeolites instead of silica fume, caused by accelerating effects of zeolites. For the concrete made with CEM II/A-S the addition of zeolites does not improve significantly the compressive strength at 28 days, the greater increment is observed by addition of silica fume. It is probably due to more finesse of CEM II/A-S, that involves a greater mechanical resistance of the samples without admixtures, in fact at 28 days we have obtained compressive strength a little advanced with the fine additions as silica fume.

The concretes made with CEM III/A-S and zeolites CaA, exhibit an increment of resistance with respect to concrete without admixture of about $9 \%$.

The greater increments are obtained at the early ages, caused by the alkali content of zeolites that accelerate the process of activation of the fly ash.

As expected, in agreement with the results of mortars, the strength of the concretes made with zeolite $\mathrm{NaA}$, was less than all the other mixes at all ages thus reflecting the fact that the sodium content influences negatively the development of hardening properties of cement concrete. The increase in strength in systems of concrete containing zeolite $\mathrm{CaA}_{S}$ and $\mathrm{CaA}_{L}$ can be explained in a way very similar to the strength increase in mortars mixes. The aggregate-matrix bond improvement induced by zeolites materials is probably the result of a combined filler and pozzolanic effect. The filler effect leads to reduction in porosity of transition zone and provides a dense microstructure and 
thus increases the strength of the system. The pozzolanic effects help the formation of bonds between the densely packed particles in the transition zone through the pozzolanic reaction with the calcium hydroxide liberated during the hydration of Portland cement to form extra binding calcium silicate hydrates which lead to further increase in the strength.

\section{Results and discussions}

Based on the results of this study it can be concluded that some artificially made zeolites can improve the strength of mortars in a way comparable to the usually addition of silica fume. The increase in the strength can be attributed to the improved aggregate-matrix bond resulting from the formation of a less porous transition zone in the zeolites concrete as silica fume concrete.

The zeolites with calcium ions can be used to produce high strength concrete in the range $60-80 \mathrm{MPa} 28$ days compressive strength, with high workability (slump flow more than $100 \mathrm{~mm}$ ), using total cementious content of about 400 $\mathrm{kg} / \mathrm{m}^{3}$. Therefore, high strength mortars and concrete with $10 \%$ calcium zeolite by weight of cement can be produced and marketed to provide technical and economical advantages in specific local uses.

\section{References}

[1] Ortega E.A., Cheeseman C., Knight J., Loizidu M., Properties of alkaliactivated clinoptilolite, Cement Concrete Research 30 (10), pp. 16411646, 2000.

[2] Poon C.S., Lam L., Kou S.C., Lin Z., A study on the hydratation rate of material zeolite blended cement pastes, Construction and building materials, 13 (8), pp. 427-432, 1999.

[3] Fragoulis D., Chaniotakis E., Stamatakis M.G., Zeolitic tuffs of Kimolos Island, Aegean Sea, Greece and their industrial potential, Cement Concrete Research, 27 (6), 889-905, 1997.

[4] Shi C., Day R.L., Pozzolanic reaction in the presence of chemical activators: Part II - Reaction products and mechanism, Cement Concrete Research, 30 (4), pp.607-613, 2000.

[5] Chan S. Y.N., Ji X., Comparative study of the initial surface absorption and chloride diffusion of high performance zeolite, silica fume and PFA concretes, Cement Concrete Composites, 21 (4), pp. 293-300, (1999).

[6] Taylor H.F.W., Cement Chemistry, Academic Press. London, 1992.

[7] Naiqian F., Properties of zeolitic mineral admixtures concrete, in: S.L. Sarkar \& S. N. Gosh Eds, Mineral Admixtures in cement and concrete. ABI Books. India pp. 393-447, 1993.

[8] Sersale R., Frigione G., Portland-zeolite-cement for minimizing alkaliaggregate expansion, Cement Concrete Research, 17, pp.404-410, 1987.

[9] Atkins M., Glasser F. P., Jack J.J., Zeolite P in cements: its potential for immobilizing toxic and radioactive waste species, Waste Management, 15 (2), 127-135, 1995. 
[10] Fu Y., Ding J., Beaudoin J. J., Zeolite-based additives for high alumina cement products, Advanced Cement Basic Materials, 3 (1), pp. $37-$ 42,1996.

[11] Gervais C., Ouki S. K., Performance study of cementitious systems containing zeolite and silica fume: effects of four metal nitrates on the setting time, strength and leaching characteristics, Journal of Hazardous Materials 93 (2), pp.187-200, 2002.

[12] Mazzasa F., Pozzolana and Pozzolanic Cements in P.C: Hewlett. Editors. Lea's Chemistry of Cement and concrete. Ed. Arnold, pp.241, 1995.

[13] Su N., Fang H.-F., Chen Z -H, Liu F.-S, Reuse of waste catalysts from petrochemical industries for cement substitution, Cement Concrete Research, 30 (11), pp. 1773-1783, 2000.

[14] Ujike I., Properties of concrete containing artificial zeolite made by chemical conversion of fly ash in R. K. Dhir. M. J. Mccarthy Editors. Concrete Durability and Repair Technology. Thomas Telford pp.123-131, 1999. 